\title{
Effect of Working Posture on the Productivity and Perceived Discomfort while Drilling on the Ceiling
}

\author{
Tae-Lim Yoon ${ }^{1}$, Jangwhon Yoon $^{2}$ \\ ${ }^{1}$ Applied Kinesiology and Ergonomic Technology Laboratory, Department of Physical Therapy, The Graduate School, \\ Yonsei University, Kangwon, 220-710 \\ ${ }^{2}$ Department of Physical Therapy, Dongshin University, Jeonnam, 520-714
}

\begin{abstract}
Objective: The purpose of this study was to compare the performance of drilling on the ceiling in three different postures (standing, standing on the ladder and supine on the height adjusted board) and the subjective responses of perceived discomfort after the drilling. Background: Overhead work has been identified as a major occupational risk factor and has been a main research subject. Method: Ten young participants drilled 20 holes at the pre-marked places on the ceiling in three different postures. The drilling duration, resting and drilling heart rate were measured. The levels of perceived discomfort at neck, shoulder, elbow, hand and overall body were asked at the end of each task. Results: The working posture affected the heart rate after the drilling. Perceived discomfort in the neck decreased significantly in supine compared to drilling on the ladder. Conclusion: The results of this study suggest that drilling in supine can be an alternative way to reduce the drilling heart rate and the level of perceived discomfort in the neck without sacrificing the productivity. Application: The results of this study would be considered when drilling on the ceiling is required in construction workers.
\end{abstract}

Keywords: Construction; Drilling; Perceived discomfort; Productivity

\section{Introduction}

Overhead work has been identified as a major occupational risk factor and has been a main research subject. Epidemiologic, physiological and biomechanical studies (Bjelle et al., 1981; Punnett et al., 2000; Sakakibara et al., 1995; Svendsen et al., 2004) found evidences to relate the overhead work and the prevalence of work-related musculoskeletal disorders, especially in the neck and shoulder joint. A dose-response relationship was discovered in the previous studies (Bjelle et al., 1981; Hagberg and
Wegman, 1987; Holmstrom et al., 1992; Svendsen et al., 2004).

Pain in shoulder of construction workers was associated with overhead work (Miranda et al., 2008). Mechanical impingement of the bicipital and supraspinatus tendons in the subacromial region may occur, especially if shoulder elevation is in the 60 to 120 range or at the end range of motion (Flatow et al., 1994). Since the tendons in these regions have atypical vascularity (Lohr and Uhthoff, 1990; Seiler Iii et al., 1989), repetitive shoulder motion and prolonged static task in these ranges can lead to tendonitis or rupture of the rotator cuff. Increasing hours of overhead

Corresponding Author: Jangwhon Yoon. Dongshin University, Physical Therapy 252 Daeho-dong, Naju, Jeonnam, 520-714.

Phone: +82-61-330-3390, E-mail: yoon@dsu.ac.kr

Copyright@2013 by Ergonomics Society of Korea(pISSN:1229-1684 eISSN:2093-8462). All right reserved.

(c) This is an open-access article distributed under the terms of the Creative Commons Attribution Non-Commercial License(http://creativecommons.org/licenses/by-nc/3.0/), which permits unrestricted non-commercial use, distribution, and reproduction in any medium, provided the original work is properly cited. http://www.esk.or.kr 
work is strongly associated with shoulder pain and disorders (Holmstrom et al., 1992; Welch et al., 1995). The mechanism of injury was explained by decreased blood supply due to increased gravity and intramuscular pressure (Hagberg and Wegman, 1987; Jarvholm et al., 1991) and mechanical impingement under the acromion (Flatow et al., 1994).

In the construction industry, overhead drilling into concrete ceiling is one of the most physically demanding tasks (Health, 2002). Rosecrance and his colleagues (Rosecrance et al., 2001) reported that $41 \%$ of a sample of construction workers in the pipe trades with high demand for ceiling drilling complained of work-related shoulder pain, with tasks performed in differing postures including directly overhead (Nanthavanij et al., 2013; Nejad et al., 2013). Drilling on the ceiling is hazardous for construction workers due to the awkward posture and prolonged static nature of task and it is typically performed in standing on the ladder or scaffold. However, identification of its relationship to work-related musculoskeletal disorders is not enough to solve the problem. Working in overhead posture is unavoidable at the construction sites. Oftentimes, the extra-weight and vibration of the hand tools make the situation worse. Rempel and his colleagues (Rempel et al., 2010; Rempel et al., 2008; Rempel et al., 2009) attempted different ways for overhead drilling. An inverted drill press and a lever design (Figure 1) could avoid the awkward posture of upper extremity and improve the worker's usability rating and the perception of discomfort during drilling (Rempel et al., 2009). However, the new interventions had minimal effect on the awkward neck posture because the workers still had to look up.

In addition, the productivity of drilling was decreased by affecting the working speed and accuracy. When the distance between tool and body increased, it obviously takes more time and effort. Working on a motorized lifting platform (Figure 2) is common at construction sites. By lying down on the lifted platform, a worker may be able to drill easier on the ceiling with hopely less discomfort and risk of injury. In this way, the distance to the ceiling form the worker can be adjusted individually and the worker can avoid the awkward posture in neck and shoulders. The productivity and the influences on the worker's body discomfort of drilling in supine position have not been tested yet, as far as we know. The purpose of this study is to suggest an alternative posture for overhead drilling with less perceived

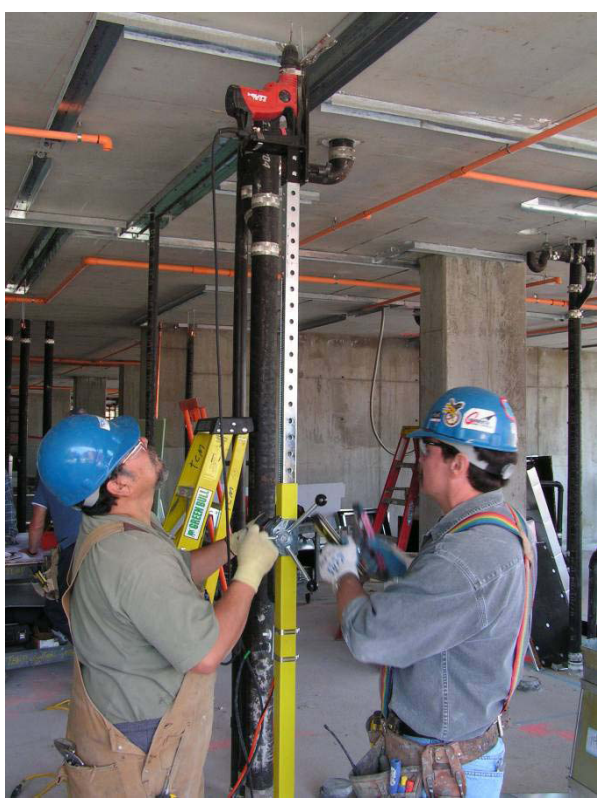

Figure 1. Inverted drill press intervention design using a rotating handle and linear gear to raise the inner (silver) column

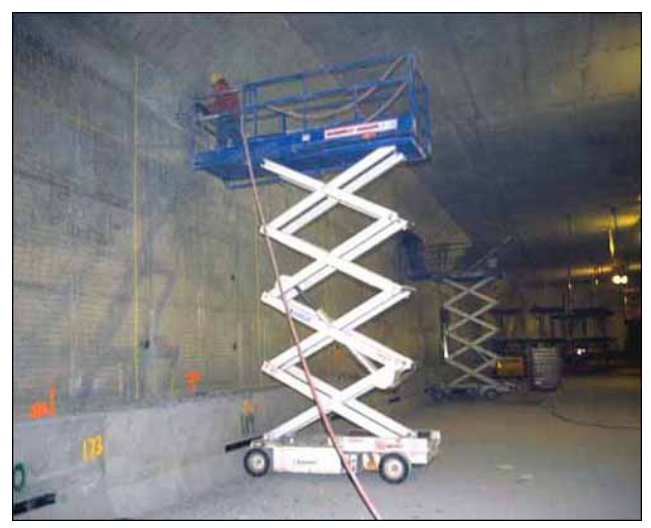

Figure 2. An example of working on a motorized lifting platform in construction industry

discomfort in the neck and upper extremity without decreasing productivity.

\section{Method}

\subsection{Participants}

Ten young (29.9+/- 7.65 years old) voluntary participants without any recent pain during the past month or any 
history of neuromuscular disorders in the neck and upper extremities were recruited. Height was $171.96(+/-12.62)$ $\mathrm{cm}$ and weight was $67.54(+/-11.46) \mathrm{kg}$. All participants were asked to read and sign the consent form approved by the Office of Institutional Board of Research Associates of New York University School of Medicine.

\section{Testing procedure}

Participants were provided with the safety goggles and a disposable mask for protection. Upon request, a lab gown and a shower cap were provided to avoid the wood dust from their clothes and hair. Sufficient (5 to 10 holes) drilling practice period was provided with demonstration prior to data collection. Standing drilling was drilling 20 holes on the height adjusted wooden board at the subject's wrist level with the arm fully elevated in standing position (Figure 3 ). Ladder drilling was drilling 20 holes on the board placed on the ceiling using a type IA ladder (Figure 4). Supine drilling was drilling 20 holes on the height adjusted board at the subject's wrist level with the arm vertically elevated in the supine position (Figure 5). 20 drilling targets were pre-marked by spraying over a punctured cardboard. The order of the drilling postures was randomized. There was a 2-minute break between drilling postures. Participants were asked to drill as fast as they can.

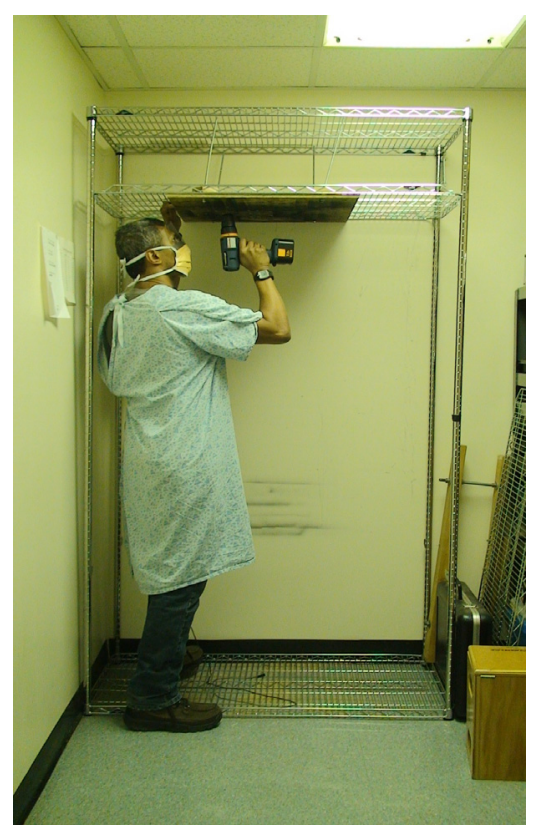

Figure 3. Picture of drilling in standing

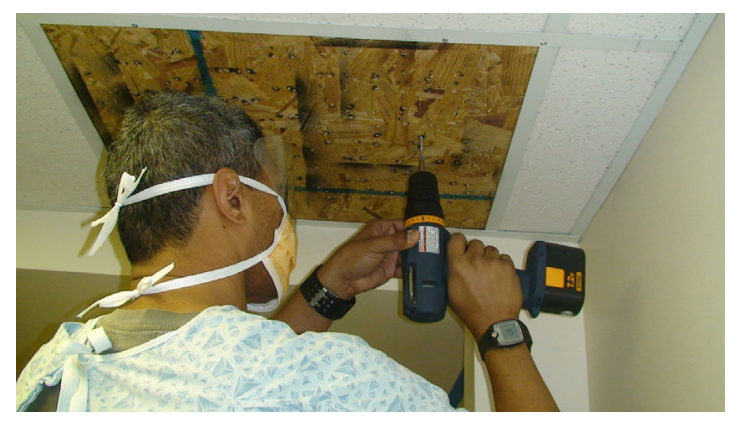

Figure 4. Picture of drilling in standing on the ladder (not shown)

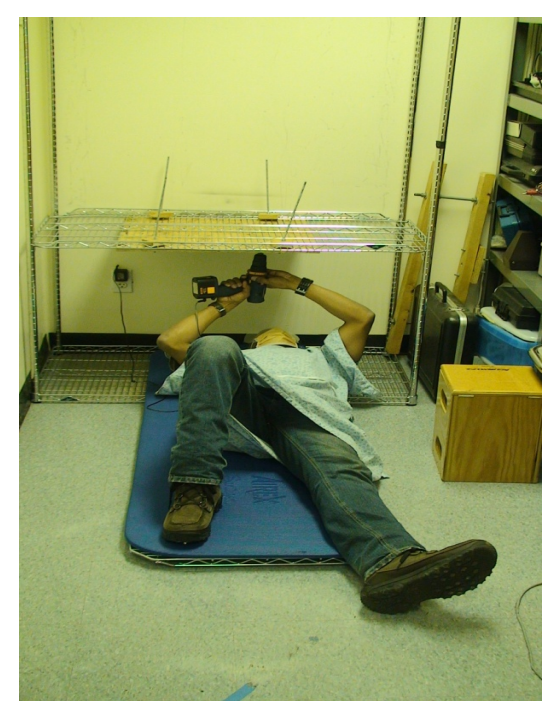

Figure 5. Picture of drilling in supine

\subsection{Instruments}

A $2.27 \mathrm{~kg}$ cordless drill (DeWalt 3/8" VSR Cordless DW991, Hampstead, MD, USA) was used. An oval-shaped drill, with the handle circumference of $14.5 \mathrm{~cm}(4.8 \mathrm{~cm}$ front to back, $3.7 \mathrm{~cm}$ wide), hard plastic near the trigger, and a rubber anti-slip grip was used throughout. A battery pack is attached at the bottom of the handle, which balances the drill in the palm when positioned vertically.

A $2.4 \mathrm{~m}$ long, type IA step ladder (136kg load capacity, Werner 6208, Greenville, PA, USA) was used for the Ladder drilling. A custom-maid moving platform will be used for the supine drilling. A stop watch was used for measuring the task duration. A heart rate monitor (Polar, HRM USA, Warminster, PA) was used for measuring resting and drilling heart rate. After all tasks were completed, the subjective 
rank (1st, 2nd and 3rd preference) of working posture was asked to subjects.

\subsection{Data collection}

The drilling duration was measured from the beginning ("ready, set and go" by tester) to the end ("done" by participants) of each task. Heart rate was recorded prior to drilling (resting heart rate) and immediately after (drilling heart rate) of each task to estimate the physiological load of drilling in different working postures. Perceived discomfort (0: comfort and 10: most discomfort) at neck, shoulder, elbow, hand and overall body was separately asked at the end of each task. Rating of perceived discomfort was found to be more reliable than the fatigue measure based on electromyography in overhead activity (Sood et al., 2007).

\subsection{Data analysis}

One-way analysis of variance with repeated measures tested the effect of working posture on the drilling duration, resting and drilling heart rate. When there was a statistically significant effect of working posture, Tukey post-hoc analysis was followed. Friedman test and pair-wise comparison was used for the perceived discomfort and the preference. SPSS version 13 was used for statistical analysis with alpha was set at .05 .

\section{Results}

\subsection{Drilling duration}

There was no statistically significant difference in the drilling duration $(p=0.923)$ by drilling postures (Figure 6).

\subsection{Heart rate}

Figure 7 demonstrates resting and drilling heart rate for each drilling task. There was no statistically significant difference in the resting heart rate prior to drilling $(p=0.072)$ by postures. However, the working posture affected the heart rate after the drilling $(p=0.017)$. Drilling in supine position had significantly lower heart rate compared to the other two postures $(p=0.044$ to drilling on the ladder and $p=0.026$ to drilling in standing). There was no significant difference in the drilling heart rate $(p=0.724)$ between ladder and standing positions.

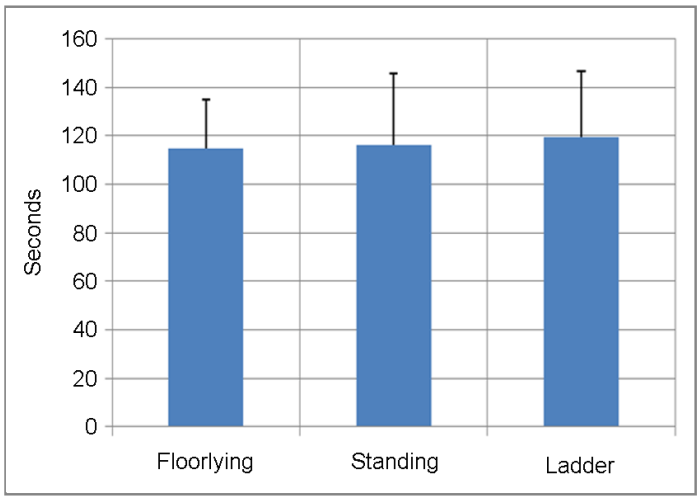

Figure 6. Drilling duration in seconds by working posture

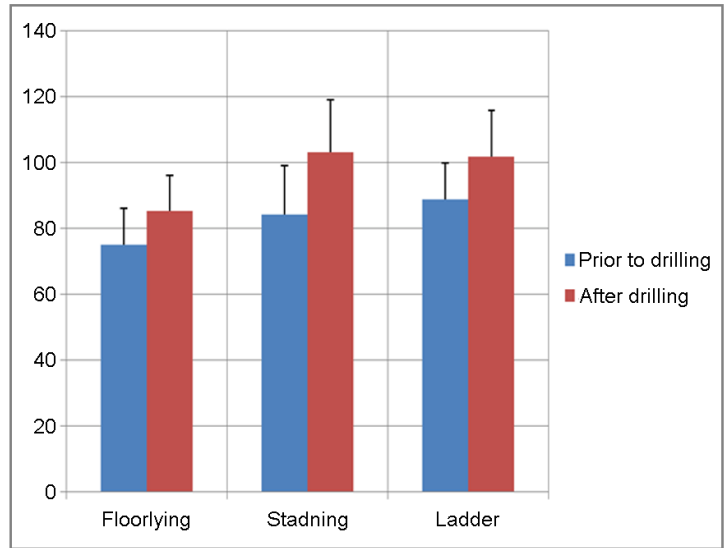

Figure 7. Resting and drilling heart rate in bits per minute by working posture (asterisk means statistically significant difference from supine)

\subsection{Level of perceived discomfort}

Figure 8 shows the level of perceived discomfort at each joint after drilling task. The levels of perceived discomfort at shoulder, elbow, hand and overall body were not statistically significant different ( $p=0.192$ for shoulder, $p=0.844$ for elbow, $p=0.868$ for hand and $p=0.130$ for overall body) between drilling postures. However, the levels of perceived discomfort at the neck was significantly affected by drilling postures ( $p=0.034)$. Drilling in supine posture had signifi- 
cantly lower neck discomfort than drilling on the ladder $(p$ $=0.040)$. There was no significant difference in the neck discomfort level between drilling in supine and drilling in standing $(p=0.096)$ and between drilling on the ladder and drilling in standing positions $(p=0.911)$. The preference rank was $1.6+/-0.84$ for drilling in supine position, 1.7 $+/-0.48$ for drilling in standing and $2.7+/-0.67$ drilling on the ladder $(p=0.025)$.

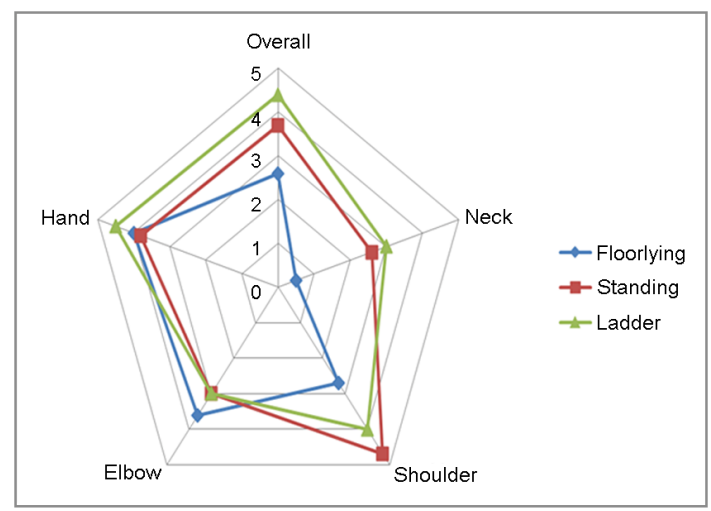

Figure 8. Rating (0-10) of perceived discomfort by working posture (asterisk means statistically significant difference from supine)

\section{Discussion}

The working posture did not affect the drilling duration. It is an important finding because it suggests the drilling in supine position can be an alternative option for construction workers when drilling many holes on the ceiling without sacrificing the productivity. In the study by Rempel and his colleagues (Rempel et al., 2010), the newly suggested drilling method (Figure 1) was feasible and decreased fatigue in the shoulder, hand, neck, and lower back. However, drilling a hole on the concrete ceiling at construction site took 79 seconds in usual overhead drilling on the ladder and 84 seconds in new intervention in their study. Comparing the drilling duration of this study, drilling 20 holes on a wooden board placed on the ceiling using the ladder took a little less than 120 seconds. It is surprisingly different and this difference can be somewhat explained with the discrepancy in drilling conditions between studies, for example, the drill size, material to drill, height of ceiling, and etc.

Heart rate is greatly influenced by body position (American Heart Association, 2012). Resting heart rate prior to drilling was somewhat affected by working posture but not reached statistical significance. The heart rate right after the drilling in supine position was significantly less than in standing and standing on the ladder. It has a considerable point because the construction sites are often very hot and physiologically demanding.

The perceived discomfort in the neck after the drilling was significantly lower in supine position than in standing on the ladder. It was fail to find statistical significance in the perceived discomfort in the other part of the body. Many of the participants reported zero perceived discomfort in the neck and much improvement in shoulder in supine position, however, did not reached statistical significance. Some of the participants reported increased discomfort in the elbow in supine position. In the previous studies (Rempel et al., 2010; Rempel et al., 2009), the subjective rating of fatigue of usual overhead drilling was greater in shoulder, hands, forearm, low back and neck in order, which agrees well with the findings of this study. On a study with electromyography (Anton et al., 2001), the further away from the head (far reach and low step), the more muscle recruitment and shoulder joint moment were observed while drilling on the ceiling on the ladder. Sood and his colleagues (Sood et al., 2007) found a non-linear relationship between drilling height and perceived discomfort, with the highest rates observed at the most extreme reaches. Couple of participants suggested raising the head side for more comfort. It may worthy to consider a reclined long sitting position for shorter distance between head and the drill, avoiding the wood dust from face, and less load on the elbow muscles. This modification can be tested in a future study which will test the kinematics and muscle recruitment with electrogoniometry and electromyography.

Limitation of this study was, firstly, the samples size was small. That may be why we fail to show the statistical significance on the perceived discomfort on the shoulder and overall body. Secondly, even the participants had some experiences in drilling, they were not professionals. The relationship between working posture and perceived discomfort in professionals can be different. Thirdly, drilling 20 holes, which took about 2 minutes, seems to be far less than what the workers do at real construction site. Drilling in 
supine or reclined long sitting position can be an alternating working posture for some workers who have problem in the neck and when there is increased physiological workload of drilling on the ceiling.

\section{Conclusion}

In conclusion, the results of this study indicate that drilling in supping position can reduce drilling heart rate and alleviate the level of discomfort in the neck without sacrificing the productivity.

\section{Acknowledgements}

This research is made possible by the generous support of the NY/NJ Education and Research Center of National Institute of Occupational Safety and Health.

\section{References}

American Heart Association. 2012. All about heart rate. Retrieved December 6, 2013, From http://heart.org.

Anton, D., Shibley, L.D., Fethke, N.B., Hess, J., Cook, T.M. and Rosecrance, J., The effect of overhead drilling position on shoulder moment and electromyography, Ergonomics, 44, 489-501, 2001.

Bjelle, A., Hagberg, M. and Michaelson, G., Occupational and individual factors in acute shoulder-neck disorders among industrial workers, British Journal of Industrial Medicine, 38, 356-363, 1981.

Flatow, E.L., Soslowsky, L.J., Ticker, J.B., Pawluk, R.J., Hepler, M., Ark, J., Mow, V.C. and Bigliani, L.U., Excursion of the rotartor cuff under the acromion. Patterns of subacromial contact, American Journal of Sports Medicine, 22, 779-788, 1994.

Hagberg, M. and Wegman, D.H., Prevalence rates and odds ratios of shoulder-neck diseases in different occupational groups, British Journal of Industrial Medicine, 44, 602-610, 1987.

Holmstrom, E.B., Lindell, J. and Moritz, U., Low back and neck/shoulder pain in construction workers: Occupational workload and psychosocial risk factors. Part 1: Relationship to low back pain, Spine, 17, 663-671, 1992.

Jarvholm, U., Palmerud, G., Karlsson, D., Herberts, P. and Kadefors, R., Intramuscular pressure and electromyography in four shoulder muscles, Journal of Orthopaedic Research, 9, 609-619, 1991.
Lohr, J.F. and Uhthoff, H.K., The microvascular pattern of the supraspinatus tendon, Clinical Orthopaedics and Related Research, 35-38, 1990.

Miranda, H., Punnett, L., Viikari-Juntura, E., Heliövaara, M. and Knekt, P., Physical work and chronic shoulder disorder. Results of a prospective population-based study, Annals of the Rheumatic Diseases, 67, 218 $-2232008$.

Nanthavanij, S., Udomratana, C., Hansawad, S., Thepkanjana, J. and Tantasuwan, W., Worksheets for computing recommended notebook computer and workstation adjustments, International Journal of Occupational Safety and Ergonomics, 19, 259-274, 2013.

National Institute for Occupational Safety and Health(NIOSH). 2002, Proceedings of a meeting to explore the use of ergonomics interventions for the mechanical and electrical trades, February 25-26, 2002, NIOSH Publication Number 2006-119. Department of Health and Human Services, Centers for Disease Control, Cincinnati, $\mathrm{OH}$.

Nejad, N.H., Choobineh, A., Rahimifard, H., Haidari, H.R. and Tabatabaei, S.H.R., Musculoskeletal risk assessment in small furniture manufacturing workshops, International Journal of Occupational Safety and Ergonomics, 19, 275-284, 2013.

Punnett, L., Fine, L.J., Monroe Keyserling, W., Herrin, G.D. and Chaffin, D.B., Shoulder disorders and postural stress in automobile assembly work, Scandinavian Journal of Work, Environment and Health, 26, 283-291, 2000

Rempel, D., Star, D., Barr, A., Blanco, M.M. and Janowitz, I., Field evaluation of a modified intervention for overhead drilling, Journal of Occupational and Environmental Hygiene, 7, 194-202, 2010.

Rempel, D., Star, D., Barr, A. and Gibbons, B., Interventions for overhead drilling in construction. In. New York, NY. p 1035-1039, 2008.

Rempel, D., Star, D., Barr, A., Gibbons, B. and Janowitz, I., A new method for overhead drilling, Ergonomics, 52, 1584-1589, 2009.

Rosecrance, J., Pórszász, J., Cook, T., Fekecs, É., Karácsony, T., Merlino, L. and Anton, D., Musculoskeletal disorders among construction apprentices in Hungary, Central European Journal of Public Health, 9, 183-187, 2001.

Sakakibara, H., Miyao, M., Kondo, T. and Yamada, S., Overhead work and shoulder-neck pain in orchard farmers harvesting pears and apples, Ergonomics, 38, 700-706, 1995.

Seiler Iii, J.G., Milek, M.A., Carpenter, G.K. and Swiontkowski, M.F., Intraoperative assessment of median nerve blood flow during carpal tunnel release with laser Doppler flowmetry, Journal of Hand Surgery, 14, 986-991, 1989

Sood, D., Nussbaum, M.A. and Hager, K., Fatigue during prolonged intermittent overhead work: Reliability of measures and effects of working height, Ergonomics, 50, 497-513, 2007.

Svendsen, S.W., Bonde, J.P., Mathiassen, S.E., Stengaard-Pedersen, K. and Frich, L.H., Work related shoulder disorders: Quantitative exposureresponse relations with reference to arm posture, Occupational and Environmental Medicine, 61, 844-853, 2004

Welch, L.S., Hunting, K.L. and Kellogg, J., Work-related musculoskeletal symptoms among sheet metal workers, American Journal of Industrial Medicine, 27, 783-791, 1995. 


\section{Author listings}

Tae-Lim Yoon: free0829@gmail.com

Highest degree: MA in kinesiology, NYU

Position title: $\mathrm{PhD}$ candidate, Department of Physical Therapy, The Graduate School, Yonsei University,

Areas of interest: Ergonomics, Biomechanics, Musculoskeletal Disorders

Jangwhon Yoon: yoon@dsu.ac.kr

Highest degree: $\mathrm{PhD}$, Graduate Program in Ergonomics and Biomechanics, NYU

Position title: Assistance Professor, Department of Physical Therapy,

Dongshin University

Areas of interest: Ergonomics, Biomechanics, Musculoskeletal Disorders
Date Received : 2013-12-04

Date Revised :2013-12-05

Date Accepted : 2013-12-24 